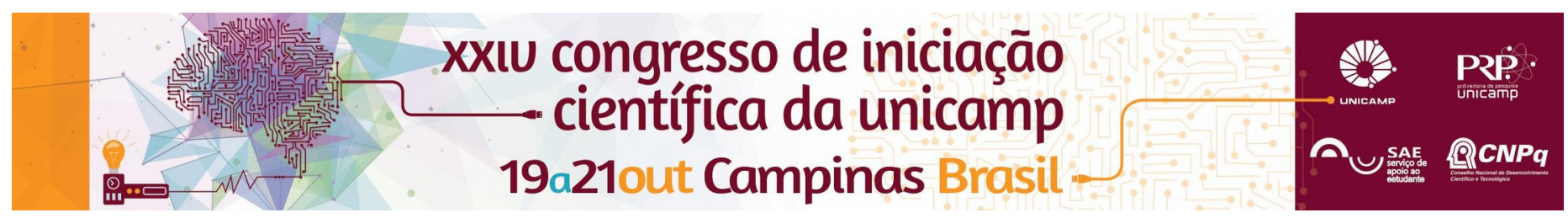

\title{
Espectroscopia do infravermelho próximo no estudo funcional do cérebro.
}

\author{
Thalia F. M. da Silva*, Giovanni H. Scavariello, Edwin J. F. Torres, R. C. Mesquita
}

\begin{abstract}
Resumo
Ao interagir com o tecido biológico, a luz pode sofrer diferentes fenômenos físicos. Na faixa de comprimentos de onda do infravermelho próximo ( 700-900 nm), a onda eletromagnética penetra o tecido biológico devido à baixa absorção e alto espalhamento. Em específico no escalpo, a técnica é bastante útil para a realização de estudos compreendidos na área de Neurociências - área que tem sido destaque em laboratórios, hospitais e centros de estudos e pesquisas de todo o mundo e que estuda o sistema nervoso tanto para adquirir qualquer tipo de conhecimento que esteja relacionado ao tema quanto para aplicações que possam servir como tratamento e compreensão de patologias que, de alguma forma, também tenham relação com a área de estudo. A espectroscopia do infravermelho próximo, ou NIRS (do inglês, Near-Infrared Spectroscopy), é uma técnica atual no Brasil que também vem ganhando cada vez mais atenção de pesquisadores e profissionais de áreas de estudos e/ou aplicações que vão desde à Física até as Neurociências. Este projeto visa um estudo dos princípios de funcionamento da técnica de NIRS, bem como uma ilustração da sua utilidade para monitorar a atividade cerebral durante um experimento de ativação funcional do cérebro.
\end{abstract}

\section{Palavras-chave:}

Espectroscopia do infravermelho próximo, NIRS, ativação cerebral, neuroimagem

\section{Introdução}

A técnica de espectroscopia no infravermelho próximo, ou NIRS (do inglês, Near-Infrared Spectroscopy), ainda emergente no Brasil, vem sendo cada vez mais utilizada para a realização do mapeamento funcional do cérebro. A introdução dessa técnica dentro da área de Neurociências tem possibilitado mais praticidade, rapidez e maior custo-benefício para os laboratórios de neuroimagem que utilizam a técnica. Tal técnica é totalmente não invasiva e dependente de alguns fenômenos que ocorrem após a emissão dessa luz no tecido biológico (YOUDH e CHANCE, 1995 apud ANJOS, 2014). Quando uma onda eletromagnética penetra um tecido biológico, principais fenômenos ocorrem: o espalhamento ou a absorção dessa onda por substâncias (ou moléculas) constituintes do meio (MESQUITA, 2009). Para o estudo funcional do cérebro com o uso de NIRS utilizam-se ondas eletromagnéticas na faixa de comprimento de onda entre $650 \mathrm{~nm}$ a $950 \mathrm{~nm}$ (MESQUITA, 2009; ANJOS, 2014), as quais são pouco absorvidas pelos componentes do tecido e facilitam o retorno (através de eventos de espalhamento) dessa luz até que seja detectada pelo equipamento, por meio de uma sonda foto-detectora localizada na região do escalpo humano. Através da detecção da luz podemos inferir quanto de luz foi absorvida pelas principais moléculas absorvedoras no tecido, na região de comprimentos de onda indicada (no caso, as moléculas de hemoglobina presentes no sangue). Por meio desta técnica é possível medir variações hemodinâmicas relacionadas à ativação neuronal humana.

\section{Resultados e Discussão}

Este projeto visa mostrar os princípios básicos de funcionamento da técnica NIRS e sua eficácia para a realização do mapeamento funcional do cérebro. Os princípios de funcionamento foram adquiridos através de estudo dirigido interdisciplinar que ilustram o potencial da técnica para a realização de estudos funcionais do cérebro. Por fim, resultados de um experimento funcional desenvolvido no laboratório de Óptica Biomédica do IFGW/Unicamp serão apresentados. O experimento envolve o monitoramento da ativação cerebral em humanos durante a realização de cálculos matemáticos.

\section{Conclusões}

A partir do estudo teórico e experimental desenvolvido é possível perceber que a técnica de NIRS é útil para o monitoramento da atividade cerebral em humanos. 